\title{
Professores em Docência no Ensino Superior: formação e desafios didático-pedagógicos no atual cenário brasileiro
}

\author{
Teachers in higher education teaching: teacher training and challenges in \\ today's Brazilian scenario
}

Gean Breda Queiros

Universidade Federal do Espírito Santo (UFES)

Kalline Pereira Aroeira

Universidade Federal do Espírito Santo (UFES)

\begin{abstract}
Resumo: Como parte de pesquisa de Mestrado Profissional em Educação, analisamos concepções e práticas professores de bacharelados e das licenciaturas com relação à formação didático-pedagógica e à docência no ensino superior, abordando esses desafios no atual cenário brasileiro. O referencial teórico pauta-se na discussão de estudos recentes sobre a formação de professores no Ensino Superior, Didática e Pedagogia Universitária. O trabalho caracteriza-se como um estudo de caráter qualitativo com pesquisa de campo analisada sob o foco de bibliografia especializada da área.
\end{abstract}

Palavras-chave: Pedagogia Universitária. Formação de Professores. Docência no Ensino Superior. Didática.

\begin{abstract}
As part of our research project for the Professional Master's Degree in Education, we analyzed what conceptions and practices teachers of bachelor's and teaching degree programs present in relation to their teaching education and profession in higher education, addressing these challenges in today's Brazilian scenario. The theoretical framework is based on the discussion of recent studies on higher education teacher education, teaching methodologies and university pedagogy. The research is characterized as a qualitative study with analyzed field research based on specialized bibliography in the area.
\end{abstract}

Keywords: University Pedagogy. Teacher Training. Higher Education Teaching. Teaching methodologies. 


\section{Como se forma um professor para a docência no ensino superior?}

Este artigo é parte da pesquisa realizada no mestrado profissional em Educação que tem, como objetivo, analisar que concepções e práticas professores de bacharelados e licenciaturas apresentam com relação a sua formação didático-pedagógica e à docência no ensino superior. Nessa direção observamos que os dados do último Censo da Educação Superior Brasileira (BRASIL, 2018) ${ }^{\mathrm{i}}$ apresentam um aumento significativo no número de professores atuando na docência do ensino superior. Em 2007, eram 317.041 docentes, subindo para 380.673 em 2017. Outro fator que chama a atenção no Censo está relacionado ao tempo dedicado à docência, em que os professores na educação superior, tanto nas instituições públicas quanto nas privadas, estão atuando mais em tempo integral e parcial do que horistas, apenas. Considerando também o aumento no número das matrículas de alunos de graduação onde há mais de 8.000 .000 (oito milhões) inscritos em 2017, a necessidade de mão de obra docente qualificada, consequentemente, aumentou.

Esses indicadores nos levam a acreditar que a busca pela atuação nos espaços acadêmicos está levando os professores a se profissionalizarem em suas áreas específicas por meio de especializações, mestrados e doutorados. Segundo os dados do MEC/INEP (BRASIL, 2018), o número de professores especialistas (74.847) está diminuindo, enquanto o número de professores com mestrado (148.427) e doutorado (157.399) cresce respectivamente. Entretanto, a formação em cursos lato e stricto sensu apenas não forma professores para o exercício do magistério superior. Os cursos em si são atributos prioritários, mas não essenciais, conforme a legislação brasileira estabelece na LDB N. 9.394/96 em seu artigo 66, parágrafo único (BRASIL, 1996) ${ }^{\mathrm{ii}}$. A essência está no processo da formação docente que ambos, profissionais e instituições, buscam firmar para superar os desafios didático-pedagógicos que a carreira impõe.

É sabido que um profissional oriundo de um curso de graduação bacharelado é um executor com habilidade técnica formado em área específica (médico, engenheiro, administrador ou economista) que, durante sua formação acadêmica, não foi preparado para o exercício da 
docência no ensino superior e se torna responsável quando assume essa profissão. Podemos dizer o mesmo sobre os profissionais oriundos dos cursos de licenciaturas, pois, em sua gênese, as formações em práticas didático-pedagógicas são atribuídas aos discentes e não aos docentes em exercício na função superior. Além do mais, a formação destes é voltada para o ensino básico e fundamental.

Ainda assim, entendemos que os professores das licenciaturas, por mais que em sua formação inicial tenham tido acesso aos conteúdos teóricos e práticos referentes ao processo de ensino e aprendizagem conforme teorizam Pimenta e Anastasiou (2014), reiteramos que, ao assumirem a docência no ensino superior, esses mesmos professores necessitam compreender as peculiaridades que a função requer nessa área. Dessa forma, é compreensível e necessário aos professores licenciados passarem pelo processo formativo docente nessa modalidade de ensino também. Aliás, é de suma importância que ambos os professores, bacharelados e licenciados, busquem compreender seus papeis no exercício da docência no ensino superior.

Essas questões nos instigam a investigar o universo formativo desses profissionais já que não há cursos regulamentados por lei que abarquem a formação de professores no ensino superior, ao passo que cresce o número de instituições nessa modalidade de ensino com ofertas de cursos bacharelados e licenciaturas, segundo os dados do MEC/INEP (BRASIL, 2018), e a formação de profissionais, com saberes técnicos específicos apenas, não supre as carências do campo pedagógico que a modalidade superior requer. É preciso formação específica para a docência no ensino superior!

Optamos por, neste espaço, refletir também sobre a afirmação de Franco (2009) quando assevera que "tenho presenciado, com muita frequência, professores que trabalham no ensino superior, comentarem que sentem falta de saberes da Pedagogia, que julgam necessários para realizarem uma prática docente mais consistente, mais agradável, mais produtiva. O termo de que se utilizam é, na verdade, que carecem de base pedagógica" (FRANCO, 2009, p. 9). Assim, entendemos ser pertinente dialogar sobre a importância e necessidade da formação de professores para a docência no ensino superior, onde os desafios didático-pedagógicos 
estão diretamente relacionados ao exercício profissional do magistério neste nível, pois sérios entraves podem ocorrer no processo de ensino e aprendizagem, principalmente pela falta de ações institucionais aplicáveis à sua formação. Da mesma forma, buscamos, por meio da revisão bibliográfica, apresentar os recentes diálogos acerca das questões que fundem a temática deste estudo.

Neste sentido, propomos as reflexões em três tópicos que se articulam. Primeiro, a docência no ensino superior e sua caracterização. Em seguida, apresentamos a didática no ensino superior, dialogando acerca de seus tratados para a aula neste espaço e, por último, trazemos para a contribuição o campo de estudo denominado Pedagogia Universitária que tem, como uma de suas ações, investigar a formação docente, seus saberes e as possibilidades que reconfiguram os processos de ensinar, aprender e avaliar a educação superior, principalmente nesse cenário de desmonte por que o sistema da educação superior brasileira está passando.

\section{Docência no Ensino Superior}

Com características distintas, a docência no ensino superior se configura como um campo profissional dotado de saberes específicos, incluindo habilidades técnicas, didáticas, pedagógicas e políticas que ultrapassam um fazer teórico apenas, mas perfazem um conjunto de ações práticas voltadas para a construção de um saber-fazer, uma unidade teoria e prática, para as atividades do mundo do trabalho, ao mesmo tempo em que busca na pesquisa a sustentabilidade para o seu fundamento, desenvolvimento e propagação.

Pensar na formação de professores para o exercício da docência superior nessas condições significa ir além de uma mera execução de uma função técnica qualquer. Exige preparo, esforço, dedicação por parte de quem assume a carreira do magistério superior. Entretanto, segundo Pimenta e Anastasiou (2014), a formação de docentes para o ensino superior no Brasil não está regulamentada sob a forma de um curso específico como nos outros níveis. De modo geral, a LDB admite que esse docente seja preparado nos cursos de pós-gradução tanto stricto como lato 
sensu, não se configurando esses como obrigatórios. Assim, as referidas autoras corroboram que, a par da questão legal, a docência no ensino superior constitui tema relevante em diferentes países e no nosso:

[...] se admite a necessidade de as instituições de nível superior desenvolverem programas de preparação de seus professores para o exercício da docência. Preparo este que os ponha a par da problemática e da complexidade do ensinar e do formar no ensino superior; do formar profissionais, do formar pesquisadores e do formar professores (PIMENTA; ANASTASIOU, 2014, p. 24).

Masetto (2002) relata que as competências para a atuação da/na docência no ensino superior exigem do candidato, antes de mais nada, que ele seja competente em uma determinada área de conhecimento, que domine a área pedagógica e que tenha exercício da dimensão política, pois ele é um cidadão, alguém que faz parte de um povo, de uma nação. Destacamos, então, que a tríade exposta por Masetto (2002) nos leva a entender a docência como um exercício de reflexão, mesclando os saberes técnicos, pedagógicos e políticos no cenário acadêmico-profissional. Pimenta (2012), por sua vez, conceitua 'professor reflexivo' abordando os estudos de Schön (1983), onde propõe uma formação profissional baseada numa epistemologia da prática, ou seja, na valorização da prática profissional como momento de construção de conhecimento, por meio da reflexão, análise e problematização desta, e o reconhecimento do conhecimento tácito, presente nas soluções que os profissionais encontram em ato.

A partir dessas colocações, trazemos a colaboração de Tardif (2014) no que diz respeito aos saberes profissionais dos professores e conhecimentos do ensino superior, onde o autor faz questionamentos sobre quais saberes, habilidades e conhecimentos são incorporados nos cursos de formação superior para o exercício da docência, declarando que há no mundo um movimento de profissionalização iii docente, buscando renovar os fundamentos epistemológicos do ofício de professor. Por outo lado, na atual conjuntura social, tratando-se de um contexto bastante paradoxal, Tardif (2014, p. 246) faz a seguinte reflexão: “considerando que se pede aos professores para se tornarem profissionais no momento em que o profissionalismo, a formação profissional e as profissões mais bem 
assentadas atravessam um período de crise profunda, é necessário reencantar a educação rumo à sociedade aprendente". Nesse contexto, concordamos com Assmann (2007) quando afirma que educar significa defender vida. E como docentes no ensino superior, devemos estar preparados junto a essa responsabilidade!

Nesse sentido, ao pensarmos sobre a formação de professores para a docência no ensino superior no Brasil, é necessário compreender as causas e os porquês desse grande contingente laboral nas diversas instituições de ensino desta natureza. Seria apenas pelo aumento da demanda, conforme explicitamos em nossas colocações iniciais? Ou até mesmo uma procura por aumento de renda salarial? Ou busca por status? Da mesma forma, quando aludimos na caracterização da docência no ensino superior, sabemos que essa é revestida de peculiaridades e sobre essas peculiaridades se determinam as ações e/ou programas de formação profissionais de professores nos meios acadêmico-institucionais, quando estas as implantam. Portanto, refletimos juntos: docência no ensino superior é profissão!

\section{Didática no Ensino Superior e sua interface no Desenvolvimento Profissional Docente}

Iniciamos nossas reflexões com as palavras da professora Terezinha Azerêdo Rios (2010, p. 54):

[...] a Didática aparece como elemento fundamental para o desenvolvimento do trabalho docente. Quantas vezes já se afirmou, no terreno do senso comum, que o bom professor é reconhecido por sua 'didática'? Claro que, utilizado dessa maneira, esse conceito é identificado como um saber fazer que é exigido do professor, além do conhecimento dos conteúdos específicos de sua área. Mas, mesmo se nos reportarmos a uma compreensão mais técnica do conceito, podemos manter a afirmação - a Didática faz parte essencial da formação e da prática docente.

Do mesmo modo, o professor necessita de uma fundamentação, ao mesmo tempo teórica e prática, para que realize satisfatoriamente o 
trabalho docente, em condições de incorporar sua própria didática, ou seja, sua prática de ensino em situações didáticas específicas conforme o contexto social em que ele atue (LIBÂNEO, 2013). É salutar, então, pesquisarmos para compreender a didática como objeto de estudo no espaço acadêmico.

Há duas colocações ao tratarmos do tema. A primeira está relacionada à didática como disciplina em cursos de licenciaturas onde seu campo de estudo se concentra no modus operandi do processo de ensinar. De acordo com Pimenta (2015), a didática enquanto disciplina nos cursos de formação de professores se coloca como possibilidade de contribuir para que o ensino, núcleo central do trabalho docente, resulte nas aprendizagens necessárias à formação dos sujeitos, equipados para se inserirem criticamente na sociedade, com vistas a transformar as condições que geram a des-humanização. E o faz, trazendo as contribuições teóricas que lhe são próprias para a análise, a compreensão, a interpretação do ensino situado em contextos, em um processo de pesquisa da realidade, com vistas a apontar possibilidades de superação. A segunda se relaciona ao seu protagonismo no exercício da docência superior, concentrando no desempenho do professor em sua atividade profissional. Propomos, pois, refletir sobre a segunda colocação.

[...] Ao estudar o ensino como fenômeno complexo e prática social, a didática busca compreender o ensino em situação, suas funções, suas implicações mais amplas; realizar ação auto-reflexiva como componente do fenômeno que estuda, (porque é parte integrante da trama do ensinar); assim, a didática, como parte do evento ensino, ajuda a criar respostas novas, assumindo ao mesmo tempo um caráter explicativo, compreensivo e projetivo, sobre a natureza do ensino, seus problemas e suas causas, suas consequências, suas possibilidades e seus limites na construção do humano (PIMENTA, 2015, p. 89-90).

A afirmação da autora nos faz pensar sobre o modo em que a didática se manifesta no espaço do ensino superior, na transmissão do conhecimento propriamente dito, ou seja, o modo como os conteúdos teóricos, metodológicos e práticos são disseminados no ambiente da sala de aula. Faz-nos pensar no desempenho docente, como este se caracteriza ao tomar corpo da teoria didática e a revelar para a materialidade do 
processo de ensino e aprendizagem, pois uma situação é o saber específico/técnico-profissional em seu autoconhecimento por formação e experiência, e a outra, completamente casada ou pelo ao menos deveria ser, é a forma de que se utiliza para repassar esse saber enquanto função docente. Esse é o nosso ponto de partida agora.

Os estudos sobre a didática nos espaços do ensino superior nesses últimos anos (VEIGA, D’ÁVILA, 2019; CANDAU, 2018; ZABALZA, 2017, 2003; VEIGA, 2015; 2014; MASETTO, 2014; D’ÁVILA, VEIGA, 2014; 2013; ANASTASIOU, ALVES, 2012) apontam um caminho para nortear as questões que embasam o desempenho docente em sala de aula, apresentando a necessidade e a importância de uma formação específica para o exercício profissional do magistério superior, pois muitos docentes ainda acreditam que somente a competência do saber técnico já os torna professores. Nesse sentido, a didática não está sendo disseminada em sua conceituação teórica apenas, mas sim debatida de forma prática, a partir de ações programadas em que as instituições de ensino superior e seu corpo docente, juntos, se propõem a estabelecer cursos próprios de formação e por adesão voluntária, ou seja, estão imbuindo a própria ação da didática pela didática, ou seja, na atividade docente conforme os estudos de Pimenta (2015).

Contudo, não falamos aqui da formação pedagógica que a maioria das instituições de ensino superior realiza a cada início do semestre letivo como os Fóruns Pedagógicos, por exemplo, ou os cursos de especializações lato sensu em Didática ou Metodologia do Ensino Superior. Esses, por sua vez, apresentam, na maioria das suas ementas, uma disciplina intitulada "Didática" que, por consequência, traz uma carga horária aquém daquela efetivamente necessária para uma formação que transpõe as peculiaridades desse campo investigativo. Por ora, nos atemos a falar sobre os cursos de extensão que estão sendo elaborados e implantados em algumas universidades brasileiras, fomentados por um novo campo de conhecimento profícuo e em expansão que é a Pedagogia Universitária.

\section{Pedagogia Universitária: um campo em construção nas ações político-institucionais da educação superior brasileira}


[...] o desenvolvimento profissional do professor pode ser concebido como qualquer intenção sistemática de melhorar a prática profissional, crenças e conhecimentos profissionais, com o objetivo de aumentar a qualidade docente, de pesquisa e de gestão. Esse conceito inclui o diagnóstico técnico ou não de carências das necessidades atuais e futuras do professor como membro de um grupo profissional, e o desenvolvimento de políticas, programas e atividades para a satisfação dessas necessidades profissionais (IMBERNÓN, 2011, p. 47).

As colocações do autor indicam os caminhos que professores e instituições devem seguir, ao passo que retratam a intenção sistemática de melhorar o desempenho profissional do professor em busca do aumento da qualidade em suas ações e a inclusão de análise técnica ou não das carências e necessidades atuais e futuras dos docentes. Esses caminhos apontam para uma prática concreta e real que já está sendo elaborada e implementada em algumas universidades brasileiras. Falamos de programas como a Pedagogia Universitária.

A universidade é uma instituição educativa, cuja finalidade é o permanente exercício da crítica, que se sustenta na pesquisa, no ensino e na extensão. Ou seja, na produção do conhecimento a partir da problematização dos conhecimentos historicamente produzidos e de seus resultados na construção da sociedade humana e das novas demandas e desafios que esta coloca. Estes, por sua vez, são produzidos e identificados inclusive nas análises que se realizam no próprio processo de ensinar, na experimentação e na análise dos projetos de extensão, por meio das relações que são estabelecidas entre os sujeitos e os objetos de conhecimento (PIMENTA; ALMEIDA, 2011).

Sendo a universidade um espaço de propagação da pesquisa, ensino e extensão, com pensamento crítico, é reconhecido o seu papel como difusora de práticas pedagógicas que alimentam sua estrutura enquanto instituição educativa. Nesse espaço, o contingente comunitário acadêmico - alunos, professores, técnicos - perfazem em grupos, seja em salas de aulas e nas demais dependências, os alicerces vitais da sua função: missão, visão, objetivos e valores.

Ao buscarmos conhecer as condições atuais de ensino no Brasil, principalmente as voltadas para as políticas da educação superior, 
caminhamos na reflexão crítica do processo formativo discente, contrapondo-se ao processo de formação dos professores. A universidade atua na continuidade da formação humana e para o exercício profissional com vistas ao mundo do trabalho, buscando a qualidade em seu processo de disseminação do conhecimento, como também atua nas pesquisas e extensão. Por outro lado, ao falar em qualidade, que é subjetiva, mas que pode ser estabelecida e mensurada por normas e padrões técnicos, a universidade e demais instituições de ensino superior estão passando a reconhecer seus papeis enquanto sujeitos na elaboração de ações e de programas que buscam formar professores críticos e reflexivos diante de situações e contextos atuais.

Nas palavras de Anastasiou (2011), as instituições de ensino superior que colocam o ensino de graduação como foco na tomada de decisões têm percebido que as mudanças necessárias aos currículos e às formas de atuação docente e discente dependem de uma série de variáveis, e uma das fundamentais centra-se no processo institucional de profissionalização do docente, seja essa profissionalização inicial ou continuada. Embora os profissionais ingressem na docência por concurso (o que se caracteriza nas instituições públicas), este nem sempre objetiva o domínio dos saberes pedagógicos necessários à docência em sua complexidade, se restringindo muitas vezes ao domínio da área a ser lecionada e à experiência com a pesquisa.

Na docência, como profissional que realiza um serviço à sociedade, o professor universitário precisa atuar de forma reflexiva, crítica e competente no âmbito de sua disciplina, explicitando seu sentido, seu significado e sua contribuição no percurso formativo dos estudantes e no projeto político-pedagógico dos cursos, coletivamente definido e vivenciado no cotidiano do ensino e da pesquisa. Projeto esse que é estabelecido a partir da identidade de cada curso, considerando as demandas da sociedade contemporânea em geral e no contexto do campo de ação próprio das áreas de saber envolvidas (PIMENTA; ALMEIDA, 2011, p. 24).

Nessa direção os estudos de Pimenta e Almeida (2011) sobre a Pedagogia Universitária, surgem no atual contexto em que as universidades e as demais instituições educativas, sofrem inúmeras pressões para se tornarem 'universidades de mercado'. As autoras 
afirmam que formar profissionais competentes nos cursos de graduação sintonizados com as demandas do mundo atual, que tenham senso de justiça social e uma identidade profunda com a cidadania democrática é tarefa que exige dos docentes do ensino superior muito mais do que repassar os conteúdos de sua área específica.

A ação docente, atualmente, está em busca de seu protagonismo nas instituições educativas; está em busca do seu caráter formativo, e as instituições de ensino superior têm a maior parcela de contribuição nessa questão, ou seja, proporcionar os programas de formação contínua de seus professores, a fim de superar os desafios didático-pedagógicos nesses tempos. Nas palavras de Pimenta e Almeida (2011), o caráter formativo da docência vem sendo cada vez mais reconhecido na sociedade atual, apontando a necessidade de se superar os discursos que a consideram fruto de uma mera vocação ou transposição das atuações exitosas no campo de atuação profissional. Ensinar é uma ação complexa que requer compreender profundamente a área específica a ser ensinada e o seu significado social; a organização do currículo como percurso formativo, o planejamento mais amplo no qual a disciplina se insere; o método de investigação de uma área que sustenta o método de seu ensino, as ações pedagógicas; os recursos adequados para o alcance dos objetivos; os modos de relacionamento com os alunos e destes com o saber; a avaliação.

Nessas colocações, as pesquisas recentes sobre a Pedagogia Universitária de Melo e Campos (2019), Melo (2018), Vieira e Almeida (2017), Pimenta e Almeida (2014), Torres (2014), Torres e Almeida (2013), Cunha e Alves (2019) e Cunha (2014, 2012, 2010, 2009, 2007, 2004) apresentam diálogos que indicam caminhos possíveis para docentes e instituições de ensino superior, à medida que passam a ter consciência de seus papeis enquanto agentes formadores de opiniões e sobre essa questão afirmam que não se forma alguém sem formação. Entretanto, poucas são as instituições de ensino superior que, de fato, estão investindo na Pedagogia Universitária até porque se configura como um campo recente de pesquisas. "Assumimos, nessa perspectiva, a necessidade de criação e fortalecimento de uma Pedagogia Universitária como política institucional que tenha como princípios ações contínuas, planejadas e realizadas de acordo com as necessidades formativas dos professores" (MELO; 
CAMPOS, 2019, p. 101). Na afirmação de Melo (2018, p. 43) observamos que:

\begin{abstract}
A Pedagogia Universitária, considerada como campo em construção, é alinhada à perspectiva de uma ciência da educação superior, capaz de prover elementos teóricos que fundamentem as reflexões sobre os processos educacionais. Deve ter na prática educativa que se realizada na universidade, seu ponto de partida para pensar e concretizar processos formativos que respondam às necessidades e demandas sociais desse nível da educação. Portanto, a ressignificação epistemológica da pedagogia universitária ocorrerá na medida em que se parta da prática pedagógica dos professores universitários como referência, para superar as contradições a ela inerentes.
\end{abstract}

A tal prática universitária a que a autora se refere deve alinhar teoria e prática na chamada práxis pedagógica conforme Pimenta (2018) estabeleceu em uma de suas obras, destacando que não há teoria sem prática e nem prática sem a teoria. Ambas são vistas de forma integrada, indissociadas. A Pedagogia Universitária, nesse contexto, busca um campo que a concretize em caráter necessário e urgente na atualidade das instituições de ensino superior, pois a partir da sua introdução no seio do planejamento administrativo-pedagógico e disseminação em programas para a comunidade acadêmica, provavelmente diminuirá as dicotomias existentes em relação à miopia que certas práticas pedagógicas ainda trazem acerca da atividade docente, pela falta de formação específica para o exercício do ensino superior.

\title{
Metodologia
}

Considerando a abordagem qualitativa, seguindo os pressupostos de Bogdan e Biklen (1994) e Minayo (2001), para quem o fenômeno educacional ocorre em contextos que precisam ser considerados pelo pesquisador, a pesquisa foi desenvolvida numa faculdade privada na região noroeste do Estado do Espírito Santo, da qual participaram docentes que atuam nos cursos de licenciatura e bacharelado (Pedagogia, Educação Física, Administração de Empresas e Administração em Análise de Sistemas) desta instituição. 
O estudo seguiu as premissas descritivo-explicativas (GIL, 1999), com técnicas básicas de coleta de dados (questionário e entrevista semiestruturada). Em relação ao tratamento e análise dos dados, foram utilizados os referenciais teóricos pesquisados em bibliografia específica, classificando a análise de conteúdo sob a proposta de Cooper e Schindler (2003, p. 347), para quem “a análise de conteúdo se dará por unidades temáticas, que são abstrações de nível mais alto, inferidas de sua conexão com uma estrutura ou padrão único no conteúdo".

\section{Resultados e Discussão}

A pesquisa de campo apresenta como principais considerações sínteses: a necessidade e importância da formação contínua de professores em docência no ensino superior em suas áreas de atuação; a implantação de ações político-institucionais que viabilizem e colaborem para efetivar projetos e programas de formação pedagógica docente em nível superior; o diálogo necessário com a Didática como elemento imprescindível aos processos de ensino e aprendizagem e com os estudos referentes à Pedagogia Universitária.

Nessa perspectiva, um profissional que se forma em um curso de bacharelado, por exemplo, não o faz para se tornar professor, mas para ser um profissional nessa área específica. Dessa forma, questionamos, qual profissional é responsável pela sua formação? Qual ou quais processos formativos um professor de um curso de bacharelado percorreu para que se tornasse apto ao exercício docente? Como ele se formou ou tornou-se professor? Teria ele participado de alguma formação contínua ou, simplesmente pelo fato de ser bacharel, já estaria habilitado para a docência? Ou até mesmo, cursou alguma especialização ou a experiência simplesmente o fez? Indagamos ainda: há instituições com cursos específicos de formação pedagógica de professores universitários? Estas têm investido em processos de formação contínua para seu corpo docente?

Ao considerarmos a trajetória acadêmica dos professores em seus processos e meios de formação em nível superior, é necessário refletir sobre a sua formação profissional e as práticas pedagógicas adotadas, pois a docência no ensino superior configura-se como um processo contínuo de 
construção da identidade docente e tem por base os saberes da experiência, construídos no exercício profissional, mediante o ensino dos saberes específicos das áreas de conhecimento (PIMENTA; ANASTASIOU, 2014).

\section{Avançando no diálogo}

Nossas inquietações referentes ao tema perfazem nossa trajetória como pesquisador na área sobre o processo formativo de professores em docência no ensino superior. A cada ano, a cada início de semestre letivo, vemos novos professores adentrando as salas de aulas sem nenhum preparo pedagógico e esse fato é uma tendência que cresce progressivamente, haja vista os indicadores do Censo apresentados. Seguindo esse pressuposto, a formação didático-pedagógica para docentes com mais tempo em exercício superior também se faz necessária à medida que o ensino e a aprendizagem se reconfiguram a todo o momento e considerando, ainda, que as metodologias ativas estão surgindo e sendo executadas, os alunos possuem outros perfis, enfim, as informações estão disponíveis em tempo real e o papel do professor agora é o de mediador nesse ambiente e cenário atravessado por mudanças constantes.

Em dados coletados para a pesquisa, observamos um grande número de instituições de ensino superior no país que não possuem elementos constituintes de uma Pedagogia Universitária estabelecida frente a programas de formação contínua para seu corpo docente, evidenciando lacunas quanto à forma do preparo pedagógico dos professores. Isso pode causar, conforme apontamos, sérios entraves no processo de ensino e aprendizagem junto ao corpo discente, à medida que só a prática ou só a teoria, dissociadas, não contemplam o rol de aspectos necessários e importantes ao estabelecimento de um ensino que se concretize perante as demandas da formação humana e saberes específicos conforme nos assegura Pimenta (2019). Posto isso, concordamos com Pimenta e Anastasiou (2014, p. 259), quando afirmam que "o avançar no processo da docência e do desenvolvimento profissional, mediante a preparação pedagógica, não se dará em separado de processos de desenvolvimento pessoal e institucional: este é o desafio a ser hoje considerado na construção da docência no ensino superior". 
Nessa conjuntura, seguimos avançando na militância de destacar sempre as causas e motivos essenciais que nos levam a defender e apostar em uma política de ações institucionais que sejam implantadas em programas de formação contínua para o corpo docente do magistério superior, mesmo em tempos de crise pelo qual passamos. Não podemos perder o foco. A qualidade do ensino está nas mãos dos docentes que lecionam e pesquisam quando estes têm apoio institucional para assim agirem. Sigamos!

\section{Referências}

ANASTASIOU, Léa das Graças Camargo. Processos Formativos de docentes universitários: aspectos teóricos e práticos. In: PIMENTA, S. G.; ALMEIDA, M. I. (Orgs.). Pedagogia Universitária: caminhos para a formação de professores. São Paulo: Cortez, 2011.

ANASTASIOU, Léa das Graças Camargo; ALVES, Leonir Pessate. Processos de Ensinagem na Universidade: pressupostos para as estratégias de trabalho em aulas. 7. Ed. Joinvile, SC: Editora Univille. 2012.

ASSMANN, Hugo. Reencantar a educação: rumo à sociedade aprendente. 10. ed. Petrópolis, RJ: Vozes, 2007.

BOGDAN, Robert. C.; BIKLEN, Sari. Investigação qualitativa em educação. Tradução de Maria João Alvarez, Sara Bahia dos Santos e Telmo Mourinho Baptista. Porto: Porto Editora, 1994.

BRASIL, LDB. Lei de Diretrizes e Bases da Educação Nacional N. 9.9394 de 20 de Dezembro de 1996. Disponível em:< http://www.planalto.gov.br/ccivil_03/leis/L9394.htm>. Acesso em: 27 fev. 2019.

Disponível

MEC/INEP. Censo da Educação Superior Brasileira (2018). <http://download.inep.gov.br/educacao_superior/censo_superior/docu mentos/2018/censo_da_educacao_superior_2017-notas_estatisticas2.pdf>. Acesso em: 26 fev. 2019.

BROILO, Cecília Luiza. Con(formando) o trabalho docente: a ação pedagógica na universidade. 2004. 267 f. Tese (Doutorado em Educação) Faculdade de Educação, Universidade Federal do Rio Grande do Sul, Porto Alegre, 2004. Disponível em:<http: https://www.lume.ufrgs.br/bitstream/handle/10183/4971/000417875.p df? sequence=1\&isAllowed=y>. Acesso em: 22 jan. 2020. 
CANDAU, Vera Maria. Didáticas. Tecendo/reinventando saberes e práticas. 1. ed. Rio de Janeiro: Editora 7 Letras, 2018.

COOPER, Donald R.; SCHINDLER, Pamela S. Métodos de pesquisa em administração. 7. ed. Tradução de Luciana de Oliveira Rocha. Porto Alegre: Bookman, 2003.

CUNHA, Maria Isabel da. Verbete pedagogia universitária. In: MOROSINI, M. C. et al. Enciclopédia de pedagogia universitária. Porto Alegre: Ries/Inep, 2004.

O lugar da formação do professor universitário: a condição profissional em questão. In: Reflexões e práticas em pedagogia universitária. Campinas: Papirus, 2007.

- Trajetórias e lugares da formação do docente da educação superior: do compromisso individual à responsabilidade institucional. GT04-Didática. Anais 32a Reunião Nacional da Anped. Caxambu, MG: ANPED, 2009.2 Disponível em:<http://32reuniao.anped.org.br/arquivos/trabalhos/GT04-5203-Int.pdf>. Acesso em: 20 out. 2019.

O campo da iniciação à docência universitária como um desafio. Reuniões Científicas. GT04-Didática. Anais $33^{a}$ Reunião Nacional da Anped. Caxambu, MG: ANPED, 2010. Disponível em:<http://33reuniao.anped.org.br/33encontro/app/webroot/files/file/ Trabalhos\%20em\%20PDF/GT04-6134--Int.pdf>. Acesso em: 20 out. 2019.

Reflexões e Práticas em Pedagogia Universitária. CUNHA, Maria Isabel (Org.). Papirus: Campinas, SP, 2012.

Quando forma é conteúdo: o campo da Pedagogia Universitária na formação de formadores. Livro 4: Didática e Prática de Ensino: Diálogos sobre a Escola, a Formação de Professores e a Sociedade. XVII ENDIPE - Encontro Nacional de Didática e Práticas de Ensino. Fortaleza, CE: $\quad$ ENDIPE, 2014. Disponível em:<http://www.uece.br/endipe2014/ebooks/livro4/47.\%20QUANDO \%20FORMA \%20\%C3\%89\%20CONTE\%C3\%9ADO_\%20O\%20CAMPO $\% 20$ DA \% 20PEDAGOGIA \%20UNIVERSIT\%C3\%81RIA \%20NA\%20FORMA\% C3\%87\%C3\%83O\%20DE\%20FORMADORES.pdf>. Acesso em: 20 out. 2019 .

CUNHA, Maria Isabel da; ALVES, Rozane da Silveira. Docência no Ensino Superior: a alternativa da formação entre pares. Revista Linhas. Florianópolis, v. 20, n. 43, p. 10-20, maio/ago. 2019. DOI: 10.5965/1984723820432019010. Disponível em: http://www.revistas.udesc.br/index.php/linhas/article/view/19847238 20432019010/pdf>. Acesso em: 19 out. 2019. 
D’ÁVILA, Cristina Maria; VEIGA, Ilma Passos Alencastro. Profissão docente: novos sentidos, novas perspectivas. Coleção Magistério: formação e trabalho pedagógico. 1. ed. Campinas, SP: Papirus Editora, 2014.

Editora CRV, 2013.

Profissão docente na educação superior. 1. ed. Curitiba:

GIL, Antônio Carlos. Como elaborar projeto de pesquisa. São Paulo: Atlas, 1999.

IMBERNÓN, Francisco. Formação docente e profissional: formar-se para a mudança e a incerteza. Trad. Silvana Cobucci Leite. Coleção questões da nossa época. v. 14. 9. ed. São Paulo: Cortez, 2011.

LIBÂNEO, José Carlos. Didática. 2. ed. São Paulo: Cortez, 2013.

MASETTO, Marcos Tarciso. Docência na Universidade. (Org.). (Coleção Magistério: formação e trabalho pedagógico). 1. ed. Campinas, SP: Papirus Editora, 2014.

Professor universitário: um profissional da educação na atividade

docente. In: (Org.). Docência na Universidade. 4. ed. Campinas, SP: Papirus $\quad 2002 . \quad$ Disponível em: https://edisciplinas.usp.br/pluginfile.php/343597/mod_resource/conten t/1/cap-1_Professor_Universitario.pdf. Acesso em: 27 fev. 2019.

MELO, Geovana Ferreira. Pedagogia Universitária: aprender a profissão, profissionalizar a docência. v. 1. 207 p. Curitiba, PR: CRV, 2018.

MELO, Geovana Ferreira; CAMPOS, Vanessa Therezinha Bueno. Pedagogia Universitária: em foco o aprendizado da docência na Universidade Federal de Uberlândia. In: FORTUNATO, I.; TAVARES, J.; CUNHA, M. I. (Orgs.). Docência no Ensino Superior: experiências no Brasil, Portugal e Espanha. - Itapetininga: Edições Hipóteses, 2019.

MINAYO, Maria Cecília de Souza. (Org.). Pesquisa social. Teoria, método, criatividade. $18^{\mathrm{a}}$. ed. Petrópolis, Vozes, 2001.

PIMENTA, Selma Garrido; ANASTASIOU, Léa das Graças Camargo. Docência no Ensino Superior. 5. ed. São Paulo: Cortez, 2014.

PIMENTA, Selma Garrido. O estágio na formação de professores: unidade teoria e prática? 11 a ed. São Paulo: Cortez, 2018.

O protagonismo da Didática nos Cursos de Licenciatura: a Didática como campo disciplinar. In: _ ; MARIN, A. J. (Orgs.). Didática - Teoria e Pesquisa. 1. ed. Araraquara: Junqueira e Marin Editores, 2015, p. 81-98.

PIMENTA, Selma Garrido; ALMEIDA, Maria Isabel de. Pedagogia universitária - valorizando o ensino e a docência na universidade. Revista Portuguesa de Educação, v. 27(2), p. 07-31, 2014. Disponível 
em:<http://www.scielo.mec.pt/pdf/rpe/v27n2/v27n2a02.pdf>. Acesso em: 01 mar. 2019.

PIMENTA, Selma Garrido. Professor reflexivo: construindo uma crítica. In: __ GHEDIN, E. (Orgs.). Professor Reflexivo no Brasil: gênese e crítica de um conceito. 7. ed. São Paulo: Cortez, 2012. cap. 1. p. 20-62.

PIMENTA, Selma Garrido; ALMEIDA, Maria Isabel de. Pedagogia Universitária: caminhos para a formação de professores. (Orgs.). São Paulo: Cortez, 2011.

RIOS, Terezinha Azerêdo. Compreender e Ensinar: por uma docência da melhor qualidade. 8. ed. São Paulo: Cortez, 2010.

SCHÖN, Donald. The reflective practitioner. Nova York: Basic Books, 1983.

TARDIF, Maurice. Saberes docentes e formação profissional. 17. ed. Petrópolis, RJ: Vozes, 2014.

TORRES, Alda Roberta. A Pedagogia Universitária e suas relações com as políticas institucionais para a formação de professores da educação superior. 2014. 295 f. Tese (Doutorado em Educação) - Faculdade de Educação, Universidade de São Paulo, São Paulo, 2014. Disponível em:<http://www.teses.usp.br/teses/disponiveis/48/48134/tde-

01102014-135153/pt-br.php>. Acesso em: 20 fev. 2019.

TORRES, Alda Roberta; ALMEIDA, Maria Isabel de. Formação de professores e suas relações com a pedagogia para a educação superior. Formação Docente, v. 5, p. 01-07, 2013. Disponível em:<https://revformacaodocente.com.br/index.php/rbpfp/article/view /92>. Acesso em: 01 mar. 2019.

VEIGA, Ilma Passos Alencastro; D'ÁVILA, Cristina Maria. Didática e docência na educação superior: implicações para a formação de professores. Coleção Magistério: formação e trabalho pedagógico. 1. ed. Campinas, SP: Papirus Editora, 2019.

VEIGA, Ilma Passos Alencastro. A prática pedagógica do professor de didática. 1. ed. Campinas, SP: Papirus Editora, 2015.

A. Lições de didática. 1. ed. Campinas, SP: Papirus Editora, 2014.

VIEIRA, Renata de Almeida; ALMEIDA, Maria Isabel de. Contribuições de Georges Snyders para a pedagogia universitária. Educação e Pesquisa, v. 43, p. 01-20, $2017 . \quad$ Disponível em:<http://www.scielo.br/pdf/ep/v43n2/1517-9702-ep-S15179702201605141169.pdf>. Acesso em: 01 mar. 2019.

ZABALZA, Miguel Ángel. Competencias docentes del professorado universitario: Calidad y desarrollo profesional. 3. ed. Madri, Espanha: Narcea Ediciones, 2017. 
O ensino universitário. Seu cenário e Seus Protagonistas. 1. ed. São Paulo: Penso Editora, 2003.

\begin{abstract}
Notas:
i Censo da Educação Superior Brasileira (MEC/INEP, 2018). Notas Estatísticas 2017. Disponível em: <http://download.inep.gov.br/educacao_superior/censo_superior/documentos/2018/censo_da_educacao_superior _2017-notas_estatisticas2.pdf>. Acesso em: 26 fev. 2019.

ii LDB - Lei de Diretrizes e Bases da Educação Nacional N. 9.394/96. Art. 66. A preparação para o exercício do magistério superior far-se-á em nível de pós-graduação, prioritariamente em programas de mestrado e doutorado Parágrafo único. 0 notório saber, reconhecido por universidade com curso de doutorado em área afim, poderá suprir a exigência de título acadêmico. Disponível em:<http://www.planalto.gov.br/ccivil_03/leis/L9394.htm>. Acesso em: 27 fev. 2019.

iii Termo empregado como expressão de uma posição social e ocupacional, de inserção em um tipo determinado de relações sociais de produção e de processo de trabalho (BROILO, 2004).
\end{abstract}

\title{
Sobre os autores:
}

Gean Breda Queiros é Mestrando no Programa de Mestrado Profissional em Educação PPGMPE da Universidade Federal do Espírito Santo - UFES. Graduado Bacharel em Administração de Empresas com Habilitação em Administração Hospitalar e Licenciado em Letras Português-Inglês.

Kalline Pereira Aroeira possui graduação em Licenciatura Plena em Educação Física pela Universidade Federal do Espírito Santo (2000), Mestrado em Didática, Teorias de Ensino e Práticas Escolares pela Universidade de São Paulo (2004) e Doutorado em Didática, Teorias de Ensino e Práticas Escolares pela Universidade de São Paulo (2009). É professora efetiva do Centro de Educação na Universidade Federal do Espírito Santo - Departamento de Teorias e Práticas de Ensino. 